\title{
Alternative Approaches for State Agencies to Address the Proposed Minimum Retroreflectivity Standards
}

\author{
Stephanie C. Vereen \\ Graduate Research Assistant \\ North Carolina State University \\ Department of Civil Engineering \\ NCSU Campus 7908 \\ Raleigh, NC 27695-7908 \\ Email: stephanievereen@earthlink.net \\ Joseph E. Hummer, Ph.D., P.E. \\ Department of Civil Engineering \\ North Carolina State University \\ Raleigh, NC 27695-7908 \\ Phone: (919) 515-7733 \\ Fax: (919) 515-7908 \\ Email: hummer@eos.ncsu.edu \\ William Rasdorf, Ph.D., P.E. \\ Department of Civil Engineering \\ North Carolina State University \\ Raleigh, NC 27695-7908 \\ Phone: (919) 515-7637 \\ Fax: (919) 515-7908 \\ Email: rasdorf@eos.ncsu.edu
}

Number of Words: 7500 


\title{
Alternative Approaches for State Agencies to Address the Proposed Minimum Retroreflectivity Standards
}

\author{
by \\ Stephanie Vereen, Joseph Hummer, and William Rasdorf \\ North Carolina State University
}

\begin{abstract}
The goal of this work was to determine, quantify, and present alternative approaches for agencies to meet the Federal Highway Administration's (FHWA) proposed minimum levels of retroreflectivity for signs. This study used current North Carolina DOT sign maintenance practices to synthesize a list of approaches to enable the state to comply with the standard. The fundamental contribution of the work lies in identifying and evaluating alternative approaches to evaluate sign retroreflectivity to ensure compliance with the standard while minimizing the cost and labor required to do so. The four approaches formulated were:

1) Nighttime visual inspection (current method),

2) Improve nighttime visual inspection procedures,

3) Implement a sign inventory management system (no visual inspection), and

4) Combination of alternatives \#2 and \#3.
\end{abstract}

It was the ultimate determination of this study that, although the most costly, alternative 4 , be adopted by agencies. It was also recommended that an evaluation be made periodically to determine what benefits and improvement in sign condition, if any, have resulted from the approaches implementation.

\section{INTRODUCTION}

In the near future, the Federal Highway Administration (FHWA) is expected to release minimum levels for sign retroreflectivity. Compliance with the standard will be costly and noncompliance will have potential liability implications. "The implementation of retroreflectivity standards would create a need for an accurate, reliable, and cost-effective method to review traffic signs in the field" (1). To date, no one has developed a system or methodology to meet the standard on a scale as vast as that faced by large state highway agencies.

The purpose of this study was to identify and evaluate alternative approaches for meeting the standard. This project identified a number of different approaches, worked with the NCDOT to select a subset of the most promising approaches, and gathered data and information to quantify the alternatives against various criteria. The goal in doing so was 
to minimize costs, reduce liability, improve safety, and comply with the proposed standards.

\section{BACKGROUND}

Beginning in 1984, the Center for Auto Safety petitioned FHWA to establish standards for retroreflectivity. Then in 1993, the Department of Transportation Appropriations Act stated that the US Secretary of Transportation should revise the Manual for Uniform Traffic Control Devices (MUTCD) to include "a standard for a minimum level of retroreflectivity that must be maintained for pavement markings and signs, which shall apply to all roads open to public travel" (2). Currently, the MUTCD states only that "regulatory, warning, and guide signs shall be retroreflective or illuminated to show the same shape and similar color by both day and night." This is the same requirement that has been present for 45 years (2).

Two reports were formulated by FHWA in 1998. The first report, Impacts on State and Local Agencies for Maintaining Traffic Signs Within Minimum Retroreflectivity Guidelines, used input from several state and local agencies to "evaluate the applicability and practicality of the minimum-maintained levels of sign retroreflectivity proposed by FHWA and the hand-held retroreflectometer that measures sign retroreflectivity" (3). The second report, An Implementation Guide for Minimum Retroreflectivity for Traffic Signs presented explanations and procedures to assist agencies in developing their own sign management systems to meet the minimum retroreflectivity requirements (4).

Also in 1998, AASHTO requested that FHWA rulemaking on the proposed minimum inservice guidelines for retroreflectivity be delayed until they can submit formal recommendations. “AASHTO's Standing Committee on Highways (SCOH) created a Retroreflectivity Task Force to look at the research and development recommendations for FHWA" (2). The Task Force formulated a mentioned policy resolution that outlined recommendations to FHWA about the guidelines and suggested four methods for evaluating retroreflectivity. The AASHTO SCOH and Board of Directors approved the resolution in 2000. Although the 2000 Millennium edition of the MUTCD did not include retroreflectivity guidelines, Section 2A.09 of the MUTCD is reserved for their addition. Thus, no formal standard is presently in place.

No numerical minimum values have been mandated yet. However, when specified, the pending retroreflective values will present several new issues to state transportation agencies responsible for sign placement and maintenance. Our purpose was to explore this impact prior to its implementation. McGee et. al. explain purpose of the standard: the principle behind such a standard is that signs and other devices that rely on internal retroreflectance to be visible should maintain a level of performance that relates to minimum driver visibility requirements. This objective is not without technical, logistical, and practical obstacles" (1). These obstacles include liability and safety issues, organizational concerns, and resource concerns such as labor and cost. 


\section{LIABILITY AWARENESS}

A concern of state agencies is that the implementation of minimum retroreflectivity standards could place agencies in positions where they are held liable for accidents. Statistics from the National Highway Traffic Safety Administration reveal that in 1999 there were 286,000 crashes due to stop sign issues alone nationwide (13). Before the possibility of minimum retroreflectivity standards, basic sight assessments to determine whether a sign still had adequate reflectivity were sufficient (8). Now that numerical standards are to be implemented, the steps or measures that are presently in place are a concern. Conducting and maintaining an inventory of devices, replacing devices at the end of their effective lives, knowing the laws relating to traffic control devices, and applying state traffic control device specifications and standards are four basic principles suggested by the ITE Traffic Sign Handbook to "significantly reduce tort liability lawsuits involving traffic control devices" (11).

Impact of Minimum Retroreflectivity Values on Sign Replacement Practices (10) performed a national survey and asked agencies if they expected "an increase in tort claim lawsuits as a result of the minimum retroreflectivity values." Of the respondents, $65.5 \%$ replied yes, their agency expected an increase in tort claim lawsuits if the proposed values are implemented. The survey respondents claimed that "whether the retroreflectivity contributed to the accident of not, the lawyers will be aware of the minimum values and will use them against the state." Still, it should be noted that there is no formal basis for this claim. To address this potential threat, and to reduce the risk of proven negligence on the state in the area of retroreflectivity and signs, it is necessary to develop viable approaches, such as a sign management plan or formal employee training, and properly implement these. More important is the need to keep adequate records to show that the duties are being performed and to establish a quality control program or periodic review to ensure they are being done correctly.

Reference (4) states, "an inventory is an essential tool for use in tort liability cases. It can provide evidence of the existence of a particular sign at a particular location and document the inspection or maintenance activity associated with the sign...some insurers have recognized the value of sign inventories in reducing liability." If there were ever litigation questioning the adequacy of a sign, an inventory would be a record of when a particular stretch of road was ridden, which signs were deficient, and when they were replaced. Another report suggests the need for formal training programs, which "improve workers' awareness, attitudes, practices, and skills." Including information about tort liability in the training program is also suggested as a tactic to improve employee effectiveness (14).

Our findings regarding liability are that no true conclusion can be drawn, at least in North Carolina. Court records are not documented in such a way that litigation involving signs can even be found. This is unfortunate but we see no way to overcome this limitation. Still, bearing in mind that signs safety enhancement will have an overall positive effect with respect to safety, we can only hope for a corresponding positive outcome regarding litigation. 


\section{DEVELOPING APPROACHES}

The project team developed a list of alternative approaches deserving detailed evaluation in several phases. First, the team compiled approaches from the literature and current practice in the area. Second, the team brought in ideas from other areas and brainstormed. Third, the team obtained feedback from its NCDOT project panel in narrowing the list.

\section{Approaches From Literature and Current Practice}

Most state agencies use some form of nighttime inspection of their signs, as the NCDOT currently does. Nighttime inspection would be a possible strategy to respond to the new guidelines. Most agencies also rely on their field personnel in the course of their other duties to be constantly on the lookout for poorly-performing signs.

Several authors have recently provided ideas on how agencies should try to meet the pending minimum retroreflectivity guidelines. The alternatives provided by AASHTO, FHWA (4) and the Texas Transportation Institute (10) include the following:

- Nighttime visual inspection using acceptable visual retroreflectivity,

- Nighttime visual inspection using minimum legibility distances,

- Implement a sign management system,

- Measure signs with a retroreflectometer,

- Total replacement of all signs.

Minimum legibility distance is the distance from the sign to the point where an observer can first read the message on the sign. The total replacement strategy would consist of simply replacing all of the signs in a given area or district at the time when the useful life expires (as specified by the manufacturer).

One other alternative promulgated by the FHWA is a retroreflectometer mounted in a van capable of making measurements during the day and at nearly highway speeds. The project team examined a prototype van and considered it to have potential on urban freeways and other places where high quality measurements must be made in a difficult environment. In the future as the technology matures, a mobile retroreflectometer may be viable in many more situations.

Clearly, AASHTO and TTI are recommending a general set of approaches that focus on and address minimum retroreflectivity. These recommendations, however, do not consider the constraints faced by various states like those relating to the degree of liability exposure, cost, and implementation issues and difficulties, among others. The next section further requires this investigation process and proposes a set of approaches that suited conditions and constraints in North Carolina. 


\section{Building a Large List of Possibilities}

With the approaches from the literature and current practice as a base, the project team tried to expand the list as widely as possible. This was a brainstorming exercise; the team attempted to apply innovations in other fields such as computing, operations research and business management to the task of locating deficient signs. The team tried to develop ways to measure signs, ways to handle sign-related data, and ways to make smart decisions with the data at hand. Among the ideas that emerged during this phase were:

- Use sign labels to determine sign age,

- Use a model to predict when a sign 'expires',

- Contract sign services out,

- Sell the signs to a responsible vendor,

- Use palm pilots to collect sign data,

- Create a certification program for sign inspectors,

- Establish financial incentives for divisions and districts to maintain high-quality signs,

- Employ auditor(s) for quality control,

- Coordinate quality control efforts with sign manufacturers, and

- Rent retroreflectivity van services.

Altogether, the team generated a list of over 200 ideas. The complete list is provided in the project report (16).

\section{Choosing Feasible Approaches to Study in Depth}

The project team reduced the complete list of over 200 possibilities down to 30 or so plausible approaches for dealing with the minimum retroreflectivity guidelines within a typical state DOT structure and using off-the-shelf components. Many of the possibilities cut from the list would have required major changes in the ways the DOTs are organized or major technological advances. Thus, these were not feasible possibilities.

The project team then presented the list of 30 or so possibilities to its NCDOT project panel for feedback. The panel consisted of experienced mid-level engineers involved in some aspect of signing. Several members worked "in the field" in NCDOT divisions, while several others worked in headquarters units with statewide responsibilities. While NCDOT does have some unique characteristics (its large size, with 78,000 miles of road, for example), the project team is confident that the project panel represented the views of many state and county DOT engineers across the U.S.

The project panel reviewed and provided feedback on the 30 or so formulated approaches. The following is a summary of the strong opinions shared by the committee about the proposed approaches: 
- Nighttime visual inspection should be continued regardless of the final strategy because they are imperative for identifying vandalized and missing signs.

- The selected approach should include a database containing, at minimum, sign location, type, inspection history, visual condition, and warranty related issues. This database would be invaluable in budgeting and scheduling.

- Contracting out sign inspection and maintenance duties is not feasible at this point due to the organizational structure of the DOT.

- Large-scale use of retroreflectometers is infeasible in a large agency due to the huge amount of labor required.

- The final strategy should not use the legibility distance method of determining sign suitability due to the training of inspectors needed to perform that method.

- Mobile retroreflectometers were not yet mature enough as a technology to use as the basis of a strategy.

- The final approach should contain a program of better training, certification, and higher job classification for sign inspectors, due to continuing loss of experienced inspectors to retirement and to the private sector.

- The final strategy should involve the development of adequate record keeping to assist in the defense of lawsuits.

\section{APPROACHES}

The clear feedback from the project panel resulted in the narrowing of the possible alternatives to four specific approaches that are to be further evaluated in the following sections. The four approaches identified was the following.

1) Nighttime visual inspection (current method),

2) Improve nighttime visual inspection procedures,

3) Implement a sign inventory management system (no visual inspection), and

4) Combination of alternatives \#2 and \#3.

The following sections further discuss each approach and describe them in detail.

\section{Approach 1: Nighttime Visual Inspection}

The first approach is to continue with the current NCDOT procedure of performing nighttime visual sign inspections using acceptable visible retroreflectivity as the judgment criteria for whether or not the signs should be replaced. The premise behind making no changes is that the current system is adequate to meet the needs of the new standard. If all inspection teams follow the state sign evaluation procedures, every three years all signs on state maintained roads would have been evaluated and replaced if necessary. Record keeping of these activities is to be resulting in data that can prove the state has taken an active effort to ensure that signs are well maintained

One significant drawback with the current method is ensuring that all inspection teams are doing the best possible job and keeping adequate records. What is still requires is a statewide system of checks and balances or quality control to be sure that the nighttime visual inspections are being performed correctly. 


\section{Costs}

Each North Carolina division uses function codes to classify expenditures pertaining to sign related activities. The codes are used to classify actions and cost out work. Each code includes materials, labor, and equipment costs to perform the specified work, except for 512, which is labor only.

Cost data for each of these codes was obtained from two of the fourteen North Carolina highway divisions for a one-year period. The total costs from the divisions were divided by the total highway mileage to determine a cost per mile. Because all of the divisions vary in size, this cost per mile figure was projected onto the overall mileage of the remaining 12 divisions to calculate a total cost to the state. These totals were divided by the total state mileage $(78,083)$ to come up with per sign costs. All mileage data was taken from NCDOT Highway and Road Mileage data statistics manual (12).

The North Carolina data shows that the average cost per division for nighttime sign inspection only (code 511) is $\$ 11,900$. The cost per sign to perform the inspections, based on the sign count estimates from the North Carolina Sign Count studies, is only $\$ 0.17$ per sign, or $\$ 167,000$ statewide for all signs. The total cost to the state to replace signs that are no longer reflective is $\$ 2,324,000$. The average cost per division is $\$ 166,000$ and the cost sign is $\$ 2.32$. The average total cost of all sign code functions per division was $\$ 574,000$. The total annual cost to the state for all sign management function is estimated to be approximately $\$ 8$ million.

According to NCHRP Report 346, an inspection program is expected to cost $\$ 5.00$ per roadway mile. This is based on labor rates of $\$ 27.50$ per hour (including overhead) for a 2-person crew, 50 percent premium pay for overtime, and a $\$ 1.00$ per mile vehicle and equipment cost. This would be for 6 hours a day at a rate of 25 miles per hour (1).

Using the NCHRP estimate of $\$ 5.00$ per mile on North Carolina DOT's 78,083 miles of road yields a total of approximately $\$ 390,000$ a year for sign inspection alone. This equates to $\$ 0.40$ per sign. This estimate is more than twice than the previous estimate of $\$ 0.17$ per sign. The higher estimate from the NCHRP Report is probably due to higher labor rates than NCDOT and the fact that NCDOT crews perform nighttime inspections at posted highway speeds whenever possible resulting in significantly less time spent performing the inspections.

\section{Approach 2: Improve Nighttime Visual Inspection}

The second approach is to maintain the current method, but make improvements to it. Nighttime visual inspection is a valid method to inspect and maintain signs; however, reforming the training program, encouraging enhanced employee performance, employing an auditor to monitor inspection quality and developing a tort claim database to help identify problem areas, are additional ways that could enhance the current inspection method. 
The end result of these improvements would be a more uniform procedure throughout the state, assurance that inspections are being performed adequately, proper record keeping is being maintained, an active attempt is being made to combat liability and reduce the unnecessary replacement of signs. Improving sign observer training would not only improve the accuracy of signs replacement, but also the accuracy of signs not needing to be replaced.

\section{Training Program}

Our recommended improvement to the current method is to establish a more uniform employee training program. The goal of the training would be to teach proper sign evaluation practices, achieve less variance in the interpretation of what is and is not acceptable retroreflectivity, educate employees on retroreflectivity and different types of sign sheeting principles and standards, review the different sign types and categories, and also teach proper data collection and record keeping. There could also be instruction on proper sign manufacturing and proper inventory maintenance to help signs in storage last longer.

A cost plus development fee for a training program developed by a state affiliated agency could range anywhere from $\$ 20,000$ - $\$ 40,000$. This cost would probably be a one-time cost to create a quality program and would be accompanied by a recurring cost each year for the training to be administered.

\section{Auditor/Quality Control/Training Position}

Another improvement is creating a full-time position for a quality control inspector or auditor. This employee would be responsible for verifying the quality of signs across the state. Their overall duties would include performing random spot checks visually at night or with a retroreflectometer in the daytime, surprise checks to accompany sign inspection crews on night rides to check their evaluation technique, and file checks to see if divisions are maintaining proper records. The same employee could also be responsible for administering sign inspection training programs.

The inspector/auditor would also spend time in the field, visiting the various divisions. This time would likely focus on two tasks: in-place sign quality control and record keeping auditing. The quality control aspect would involve measuring a sample of signs with a retroreflectometer during the day and performing visual inspections at night. A specified percentage of the measured signs would have to comply with the proposed retroreflectivity standards in order for the division to receive a satisfactory rating for sign inspection practices. The auditing activity would involve reviewing the records made during the nighttime sign inspections and any maps or plans the division uses to organize their efforts. Whether or not critical signs are replaced in a timely manner, how many signs are not replaced each year, and similar information would be collected.

The employee's training duties, although not necessary executed every year, would require a considerable effort, probably 3 months. These tasks would include organizing 
registration, preparing materials, and might also include teaching. This work would be performed in conjunction with the state's training administrator and staff.

\section{Tort Claims Database}

Another improvement is a tort claims database to keep a record of claims that are made and the nature of the claim. The database would include claims filed against the DOT, the reason for the claim (including issues leading up to the claim), the amount of the claim, the legal course of action taken (settled, dismissed, court, etc.), the award amount if any, and other information. Currently, the only way to assess how many past cases have involved sign visibility is to manually search through tort claims maintained by the courts, a daunting and impractical task. Presently, this makes it nearly impossible to assess liability with respect to signs.

However, a database could provide historical data that could be used to protect the state against future liability claims. It can also be used to generate statistical data about how many claims made are related to signing (or other) issues, whether the sign was damaged, missing, not visible, or some other reason. Reports could be issued on a yearly basis to help DOT personnel to identify the causes of claims and situations that lead to claims and to identify if any procedures can be changed or updated to prevent similar claims in the future.

Developing a Tort Claims Database would involve Database Management Services (DMS) for analyzing, planning, and creating a database management system. Exactly what and how much information would be included in the database is a critical factor in the planning element. Before any system design is ever attempted, an initial planning and analysis phase is needed. The planning period would determine the objectives and needs of the desired database, who will operate and maintain it, and other design and operational issues. The cost of the labor, equipment, and other tasks require to start a database project would be determined during this planning period.

Typically the cost of a basic database system ranges from $\$ 80,000$ to $\$ 100,000$. The cost varies based on factors such as what type and how much information is to be stored and how tightly the system is to be integrated into existing systems. This cost includes creation and implementation of the system but does not include any training, rollout, or operational costs. In addition to the development, ongoing costs would include the cost of an employee to enter data and monitor the system and the cost of computers and storage media.

\section{Inspection Frequency}

Why are Interstates and primary roads, which contain the least number of critical signs (stop, red, yellow) evaluated most often? $93 \%$ of the stop signs in the primary road sign count $(5,6)$ were on rural state routes, which (although considered to be a part of the primary system) are in rural areas where there is significantly less installed lighting. The signs on these roads are inspected only every 3 years which is a substantial time period ( 3 years is nearly $43 \%$ of the 7 year estimated life of engineer grade sheeting). 
Unfortunately secondary road sign inspection is even more time consuming (because of stop signs, traffic lights, more concentrated traffic flow, and dirt and winding roads). A frequency comparison was conducted considering all roads being inspected every other year (50\% of all signs on all road types being evaluated every year). Table 1 displays the results of the comparison. The comparison is based on warning signs (yellow and orange background sheeting) only. Based on these results one suggestion would be to evaluate Interstates every other year instead of every year.

Table 1: Evaluating Warning Signs on Interstates Every Year (100\% each year) vs. Every Other Year (50\% each year)

\begin{tabular}{|c|c|c|c|c|}
\hline \multirow[b]{2}{*}{ YEAR } & \multicolumn{2}{|c|}{ EVALUATION EVERY YEAR } & \multicolumn{2}{|c|}{$\begin{array}{c}\text { EVALUATION EVERY } \\
\text { OTHER YEAR } \\
\end{array}$} \\
\hline & $\begin{array}{l}\text { \% of signs not } \\
\text { meeting } \\
\text { proposed } \\
\text { standard }\end{array}$ & \% Accuracy & $\begin{array}{l}\text { \% of signs not } \\
\text { meeting } \\
\text { proposed } \\
\text { standard }\end{array}$ & \% Accuracy \\
\hline $\mathbf{0}$ & 3.58 & 81.1 & - & - \\
\hline 1 & 3.54 & 83.2 & 7.86 & 81.0 \\
\hline 2 & 2.84 & 83.5 & - & - \\
\hline 3 & 2.33 & 83.7 & 6.74 & 81.8 \\
\hline 4 & 1.93 & 83.9 & - & - \\
\hline 5 & 1.60 & 83.3 & 5.60 & 82.9 \\
\hline 6 & 1.47 & 83.0 & - & - \\
\hline 7 & 2.32 & 82.9 & 3.11 & 81.8 \\
\hline$\overline{\mathbf{0}}$ & 2.37 & 83.2 & - & - \\
\hline 1 & 2.26 & 83.3 & 1.81 & 83.2 \\
\hline 2 & 2.13 & 83.4 & & \\
\hline 3 & 2.03 & 83.4 & 1.96 & 83.4 \\
\hline 4 & 2.00 & 83.3 & & \\
\hline 5 & 2.00 & 83.2 & 1.78 & 83.4 \\
\hline 6 & 2.13 & 83.2 & & \\
\hline 7 & 2.15 & 83.3 & 1.58 & 82.6 \\
\hline
\end{tabular}

Table 1 is based on 3,375 warning signs on Interstates and 1,687 signs being evaluated each year (50\% each year). Year 0 represents the year in which standards are actually implemented. Also in Year 0, it is assumed that an equal number of signs were replaced every year for seven years prior. When the cycle starts over again in Year 0, the number of signs replaced each year is drawn from the actual numbers generated from the previous years 0 through 7 .

Based on the evaluation, the percent accuracy, which includes the correct number of signs chosen to be to stay in place and be replaced, remains about the same. However, once the second evaluation cycle begins, the percent of signs not meeting standards is less when the signs are evaluated every other instead of every year. This is due to the 
fact that for the every other year evaluation, for the first seven-year cycle, it is assumed that an equal number of signs were replaced every year; however, when the second seven-year cycle begins and the numbers generated by the spreadsheet are used, the calculations show that no signs were replaced every other year. This causes the total number of signs considered in previous years to decrease, thus creating the dramatic change in the percent of signs not in compliance.

At the end of 2 cycles (14 years), there is only a $0.57 \%$ difference in the percent of signs potentially not in compliance. This is equal to only 19 signs. This minimal difference is probably due to the low number of signs in-place on interstates. Altering the evaluation frequency would not affect such a low number significantly.

A comparison was then made for stop and warning signs on secondary roads being evaluated every two years (50\% every year) instead of every three years (about 33\% every year). A considerable change in the percent of signs potentially not in compliance was made by performing the comparison. After two cycles (14 years), warning signs changed from $4.38 \%$ to $1.58 \%$. The $2.8 \%$ difference is equal to about 2,800 warning signs on secondary roads. There was also a $2.8 \%$ change for stop signs, which changed from $4.39 \%$ to $1.58 \%$. The difference is equal to about 1,400 stop signs on secondary roads.

Altering the frequency at which roads are evaluated would increase the sign inspection workload each year. Although Interstates would be evaluated less, the frequency at which secondary roads are evaluated would increase and there are considerably more miles of secondary roads than Interstate roads. At the current inspection frequency, approximately 29,000 miles are evaluated each year. If the altered inspection frequency were adopted, this would increase to 39,000 miles being evaluated each year, $33 \%$ increase of 10,000 miles. Adopting the inspection frequency change would result in an increase in the sign inspection costs per year. The cost presently is $\$ 2$ per mile. So an additional 10,000 miles would cost an additional $\$ 20,000$ a year to change the frequency of nighttime visual inspection.

As stated before, 3 years is nearly $43 \%$ of a sign's expected useful life. Is changing the evaluation frequency more efficient than replacing signs that are questionable and may not remain adequate until evaluated again? If, on a secondary road, 100 signs are evaluated and 40 of those are questionable (i.e. still visible this year, but maybe not still in the next two years when it will not be evaluated), would riding the same road more often be more economical than replacing the signs?

If all 40 signs are replaced because it is anticipated that they will become inadequate before the next inspection the additional cost incurred (assuming approximately $\$ 20.00$ per sign for inspection) would be $\$ 800$. At a cost of $\$ 0.16$ per sign to evaluate, only $\$ 6.40$ more per year would be spent evaluating these signs more often as opposed to replacing them early because of less frequent inspection. 


\section{Total Costs of Suggested Improvements}

Table 2 outlines the total costs of the suggested improvements that have been discussed for approach 2 .

Table 2: Total Costs for Approach 2

\begin{tabular}{|l||c|c|}
\hline \multicolumn{1}{|c||}{ IMPROVEMENT } & INITIAL COST & $\begin{array}{c}\text { ONGOING COST } \\
\text { (per year) }\end{array}$ \\
\hline CURRENT METHOD & $\$ 167,000 /$ year & $\$ 167,000$ \\
\hline Training & $\$ 20,000-\$ 40,000$ & - \\
\hline Program Development & - & $\$ 5,000$ \\
\hline Cost of Training & $\$ 74,900$ & $\begin{array}{c}\$ 64,600 \\
{[+2-4 \% \text { raise each }} \\
\text { year }]\end{array}$ \\
\hline $\begin{array}{l}\text { Quality Control Auditor } \\
\text { Employee }\end{array}$ & $\$ 1600-\$ 3600$ & - \\
\hline Tort Claims Database & $\$ 80,000-100,000$ & - \\
\hline Planning and Analysis & - & $\$ 1000 /$ year \\
\hline $\begin{array}{l}\text { Creation and } \\
\text { Implementation }\end{array}$ & $\$ 20,000$ & $\$ 20,000$ \\
\hline System Maintenance & - & - \\
\hline Alter Inspection Frequency & $\$ 363,500-\$ 405,500$ & $\$ 257,600$ \\
\hline TOTAL INITIAL & $\begin{array}{l}\text { TOTAL ONGOING }(\text { Per } \\
\text { year) }\end{array}$ &
\end{tabular}

The improvement costs for the initial year and the ongoing costs per year include the current estimated cost of $\$ 167,000$ to perform nighttime visual inspections.

\section{Approach 3: Establish A Sign Inventory Management System}

The third approach suggested by the project team is to establish a sign inventory that would keep record of, at minimum, sign type, sheeting type, and sign location. This approach would be used in addition to the nighttime visual inspection method. Conducting and maintaining an inventory of devices is one of the four basic principles suggested by the ITE Traffic Signing Handbook to "significantly reduce tort liability lawsuits involving traffic control devices" (11).

In addition to knowing whether a sign has adequate retroreflectivity, it is essential for personnel to know the exact position of all signs, as well as more detailed physical information about the signs. A comprehensive sign inventory can target signs for replacement based on installation dates, identify problems by tracking maintenance records, minimize tort liability by providing evidence of sign existence and maintenance, assist with sign planning and budgeting by knowing how many aging signs are approaching replacement, and maximizing productivity by combining work orders with 
the inventory (4)). A sign inventory can also assist with creating more efficient budgets for sign management practices.

A validation system to check the accuracy of night rides using retroreflectometers could be implemented in conjunction with the inventory. A sample of signs would be identified each year and be measured with a handheld retroreflectometer unit. The measured values would be compared with the visual inspection results to validate the visual inspections and to identify personnel inspection training needs.

Data collection methods include manual field collection, laptop field collection, photologging, and videologging. Manual field collection and laptop field collection are the same except that the first involves entering data in the office and the second involves entering data directly into the software in the field. Both methods can use GPS receivers (which were found to be 20 percent faster for obtaining location reference data for urban signs than any other measurement method (4) to obtain location data. Photologging and videologging are other methods of data collection. Cost data for each method is outlined in the following section.

\section{Data Collection Costs}

A prototype customized sign inventory management system was developed by the North Carolina State University Department of Civil Engineering. The goals of the development effort were to determine the feasibility of a sign inventory that would address the issue of retroreflectivity being performed (using GPS technology) and to determine time and costs related to the creation and implementation of such an inventory. The study determined the time (in minutes per sign) required to collect data to populate a customized sign inventory system meeting retroflectivity evaluation needs. Three separate input rates were calculated; two were for collecting data to be entered into a simple data dictionary (first on Interstate and primary roads, and then, on secondary roads). The third rate was for collecting data for a more complex data dictionary, which requires the surveyor to get out of the vehicle to acquire the data.

For the simple data dictionary, signs located on Interstate and primary routes were inventoried at an average rate of 0.59 minutes or 35 seconds per sign and secondary routes were inventoried at an average rate of 0.75 minutes or 45 seconds per sign. Given that there are approximately 400,000 primary (5) and 615,000 secondary (6) road signs the projected amount of time required to populate a North Carolina inventory using the simple data dictionary attributes would be 3,900 hours for primary and 7,700 hours for secondary totaling 11,600 hours. This corresponds to approximately 1,450 eight hour man-days, 73 weeks, or 1.5 man-years.

Results for the complex data dictionary involve getting out of the car to obtain the installation date from the sticker on the back of the sign. The same stretch of a secondary road was evaluated twice, once to collect the simple data dictionary attributes and a second time to collect the additional complex data dictionary attributes. The simple data took approximately $35(0.58)$ seconds per sign to collect and the complex data took 67 (1.11) seconds to collect, a $90 \%$ increase. 
Assuming that an entry-level signing employee or temporary intern has a salary rate of $\$ 10$ per hour, the cost for two people to complete the 11,600 hours of simple data dictionary attribute collection would be $\$ 232,000$ plus indirect costs such as equipment, travel time and mileage.

Table 3 shows various cost ranges for manual, photolog, and videolog inventory data collection methods based on figures extracted from the literature (1, 17). Manual data collection is assumed to be obtained by a crew of at least two individuals riding by each sign and recording data. Photologging is created by taking one photo image every 0.01 mile, resulting in 100 photos per mile. Each 35-mm still frame of color is used to create positive prints on 35-mm filmstrip and edited onto small reels for viewing on $35-\mathrm{mm}$ stripfilm motion-still analyzers. The resulting film creates a continuously running presentation of the roadway. Videologging is an actual video of the roadway created using special van mounted video cameras.

Table 3: Cost Estimates for Sign Inventory Data Collection for NC

\begin{tabular}{||l|c|c|c|}
\hline \multicolumn{4}{|c|}{ Range of Cost to Create an Inventory Based on Total Miles (Source 1) } \\
\hline \multicolumn{1}{|c|}{ Area Type (NC miles) } & Manual & Photolog & Videolog \\
\hline Urban (6,976) & $\begin{array}{r}\$ 558,000- \\
\$ 942,000\end{array}$ & $\$ 314,000-\$ 488,000$ & $\$ 209,000-\$ 488,000$ \\
\hline Rural (71,106) & $\begin{array}{l}\$ 1,067,000- \\
\$ 3,200,000\end{array}$ & $\$ 1,778,000-\$ 2,133,000$ & $\begin{array}{r}\$ 1,067,000- \\
\$ 1,778,000\end{array}$ \\
\hline TOTAL (78,083) & $\begin{array}{l}\$ 1,625,000- \\
\$ 4,142,000\end{array}$ & $\$ 2,092,000-\$ 2,621,000$ & $\begin{array}{c}\$ 1,276,000- \\
\$ 2,266,000\end{array}$ \\
\hline \hline \multicolumn{2}{|c|}{ Range of Cost to Create an Inventory Based on Total Miles (Source 17) } \\
\hline $\begin{array}{l}\text { Urban area, high density } \\
(3,488)\end{array}$ & $\$ 469,000$ & $\$ 242,000$ & $\$ 240,000$ \\
\hline $\begin{array}{l}\text { Urban/suburban area, } \\
\text { moderate sign density } \\
(3,488)\end{array}$ & $\$ 288,000$ & $\$ 163,000$ & $\$ 109,000$ \\
\hline $\begin{array}{l}\text { Rural/small urban area, low } \\
\text { sign density (35,553) }\end{array}$ & $\$ 1,558,000$ & $\$ 1,024,000$ & $\$ 786,000$ \\
\hline $\begin{array}{l}\text { Rural area, very low sign } \\
\text { density (35,553) }\end{array}$ & $\$ 543,000$ & $\$ 834,000$ & $\$ 570,000$ \\
\hline Total (78,083) & $\$ 2,858,000$ & $\$ 2,263,000$ & $\$ 1,705,000$ \\
\hline
\end{tabular}

*Assumed half of NC urban miles were high density and half were moderate density ** Assumed half of NC rural miles were low density and half were very low density

The costs contained in this table represent data collection costs only; they do not include any long-term maintenance costs associated with the systems or with the purchase or creation of any necessary software or hardware. 


\section{Total SIMS Costs}

Adoption and implementation of a sign inventory management system is a major undertaking. Considerable costs and labor would be involved in order to create a usable, sustainable, system that will be of some benefit in the long run. However, the benefits of a sign management system include assisting with the tracking of signs and budgeting, ensuring that no signs are in place for longer than their anticipated life, providing maps and data to be used during nighttime inspections, and generating statistics about sign replacement.

The costs associated with creating, populating, and maintaining an inventory depends on the combination of software, hardware, collection methods, and maintenance options chosen. Software costs would range from $\$ 0$ to $\$ 4800$. Data collection costs could range from $\$ 228,000$ (labor only) to populate an inventory (as determined from the results of the GPS Sign Inventory Study method) to $\$ 1.6$ - \$4.1 million as (determined from existing literature). Other equipment may be necessary, depending on the combination of necessities chosen, such as GPS equipment. Training sessions would also be necessary to educate employees on how to use the new system. Ongoing maintenance and upgrades costs would also be required.

Over time, the "initial costs of developing the inventory will prove to be cost effective over the long run as it will minimize the costs of inspection and allow the responsible office to more effectively manage their system." A well-developed and maintained sign inventory management system will also serve as "a good defense against a negligence suit because it shows an organized attempt to maintain signs" (15).

\section{Approach 4: Combination}

Even if an inventory were established and maintained it would not be possible to completely eliminate visual sign inspection because the inventory would not be able to identify missing signs. So approach four is a combination of the second approach (to continue with the current method of nighttime sign inspection but make improvements to the training and record-keeping) and the third approach (implementing a sign inventory). Neither of the two approaches is dependent on the other, but combining the two could provide the benefits of both.

By combining two of the previous approaches, some actions necessary to each one individually could be combined for costs savings. For example, the training class from approach two could be expanded to teach sign inspection employees how to maintain the inventory system and use the equipment and hardware necessary to populate and maintain it. Also, if two and three are combined, then the employee position created from approach two could be responsible for overseeing the data collection process and for long-term maintenance of the inventory software and hardware. Their rotational visits to locations throughout the state, in addition to the duties previously outlined, could ensure that the inventory system is being properly maintained providing impromptu training for new employees, and ensuring that the hardware in each division is adequate. 
But most importantly, retroreflectivity values measured from the sample of signs collected by this employee could be entered into the inventory system.

\section{Costs}

The costs would include the total and ongoing costs of both approaches. Table 4 shows these values.

Table 4: Costs Associated with Approach \#4

\begin{tabular}{|c||c|c|}
\hline & INITITAL & ONGOING (per year) \\
\hline \hline APPROACH 2 & $\$ 363,500-\$ 405,500$ & $\$ 257,600$ \\
\hline APPROACH 3 & & $\$ 0-\$ 800$ \\
\hline Software & $\$ 0-\$ 4000$ & - \\
\hline Data Collection & $\$ 232,000-\$ 2.85 \mathbf{M}^{*}$ & $\mathbf{\sim 2 5 8 , 0 0 0}$ \\
\hline \hline TOTAL & $\mathbf{\$ 5 9 1 , 5 0 0}-\mathbf{\$ 3 . 2 6} \mathbf{M}$ & \\
\hline
\end{tabular}

* Average of $\$ 1.6$ - $\$ 4.1$ million

This combination approach is the most costly of the four approaches examined. However, this approach would provide the maximum benefits: a sign inventory management system is created, employee training is enhanced with the anticipated results of better visual signs inspection techniques and results, and a new position is created to ensure that the suggested improvements are continued and that the inventory system is properly maintained.

\section{CONCLUSIONS AND RECOMMENDATIONS}

Ensuring that proper retroreflectivity is achieved for all signs, whether covered by the standard or not, is an important issue to state agencies. Signs play an integral part in driver safety, especially at night when retroreflectivity is most important because of the decrease in natural light sources.

This paper, based on a literature review and research study, has attempted to formulate approaches to sign inspection in order to ensure compliance with the forthcoming retroreflectivity standards, to improve driver safety, reduce accidents, and reduce the potential of tort claims and liability against states.

\section{Objectives Met by Alternate Approaches}

Table 5 lists the 14 desired objectives of the four approaches and indicates which approaches meet each objective. Of the objectives considered, one of the most important is "includes better record keeping to defend against liability claims." Continuing with the current method (approach 1) is the only approach that does not meet this objective. None of the approaches reduce the amount of labor required, but using the same amount of (or more) labor may lead to reduced costs in other ways. 
Note that Table 5 expresses the four original implementation obstacles (from the Background Section) in different forms. These use liability and safety issues, organizational concerns, and resource concerns. It is worth repeating here that liability and safety cannot directly be measured. The underlying assumption that better signing will result in greater safety is understood but its quantification remains undone. Organizational concerns are highly dependent on each individual State DOT. Finally, the availability of labor and dollars affects any approach to a significant degree.

Approaches 2 and 4 were identified as ' $\mathrm{Y}$ ' for generating numerical retroreflectivity data. This is not for the entire population of signs in North Carolina; only for a sample of signs that would be measured by the new employee. The research committee noted that they would like for the signs legibility distance method not be used nor for sign inspection services to be contracted out; all of the approaches meet these objectives.

Table 5: Approach Objectives

\begin{tabular}{|l|c|c|c|c|}
\hline \multicolumn{1}{|c|}{ OBJECTIVES } & $\mathbf{1}$ & $\mathbf{2}$ & $\mathbf{3}$ & $\mathbf{4}$ \\
\hline Minimizes/reasonable cost & $\mathrm{N}$ & $\mathrm{N}$ & $\mathrm{N}$ & $\mathrm{N}$ \\
\hline Improves/increases compliance with proposed standards & $\mathrm{N}$ & $\mathrm{Y}$ & $\mathrm{Y}$ & $\mathrm{Y}$ \\
\hline Use technology & $\mathrm{N}$ & $\mathrm{Y}$ & $\mathrm{Y}$ & $\mathrm{Y}$ \\
\hline Reduce required labor & $\mathrm{N}$ & $\mathrm{N}$ & $\mathrm{N}$ & $\mathrm{N}$ \\
\hline Integrates current resources and procedures & $\mathrm{Y}$ & $\mathrm{Y}$ & $\mathrm{Y}$ & $\mathrm{Y}$ \\
\hline $\begin{array}{l}\text { Helps do other functions (data can be used for other } \\
\text { purposes) }\end{array}$ & $\mathrm{N}$ & $\mathrm{N}$ & $\mathrm{Y}$ & $\mathrm{Y}$ \\
\hline Generates numerical retroreflectivity data & $\mathrm{N}$ & $\mathrm{Y}$ & $\mathrm{N}$ & $\mathrm{Y}$ \\
\hline $\begin{array}{l}\text { Continues nighttime ride } \\
\text { (Identifies missing and vandalized signs) }\end{array}$ & $\mathrm{Y}$ & $\mathrm{Y}$ & $\mathrm{Y}$ & $\mathrm{Y}$ \\
\hline Creates a Database & $\mathrm{N}$ & $\mathrm{N}$ & $\mathrm{Y}$ & $\mathrm{Y}$ \\
\hline Use legibility distance method & $\mathrm{N}$ & $\mathrm{N}$ & $\mathrm{N}$ & $\mathrm{N}$ \\
\hline Contract out sign inspection or maintenance & $\mathrm{N}$ & $\mathrm{N}$ & $\mathrm{N}$ & $\mathrm{N}$ \\
\hline $\begin{array}{l}\text { Contains program of better training/certification for sign } \\
\text { inspectors }\end{array}$ & $\mathrm{N}$ & $\mathrm{Y}$ & $\mathrm{N}$ & $\mathrm{Y}$ \\
\hline $\begin{array}{l}\text { Does not use handheld or van-mounted } \\
\text { retroreflectometers }\end{array}$ & $\mathrm{Y}$ & $\mathrm{Y}$ & $\mathrm{Y}$ & $\mathrm{Y}$ \\
\hline $\begin{array}{l}\text { Includes better record keeping to defend against liability } \\
\text { claims }\end{array}$ & $\mathrm{N}$ & $\mathrm{Y}$ & $\mathrm{Y}$ & $\mathrm{Y}$ \\
\hline \hline 'Y' TOTAL & 3 & 7 & 7 & 9 \\
\hline
\end{tabular}

The overall desired outcome of whichever approach is pursued by a state is to ensure that all signs possess adequate retroreflectivity at all times. Each approach has a variety of w 


\section{Recommendations}

Based on the results and conclusions, it was determined that a combination of approach 4, the combination of approach 2 (improve nighttime visual inspection) and approach 3 (implement a sign management system) was most suitable in North Carolina. Although most costly, it achieves the most desired objectives. It would create a sign management system, improve sign inspector training (with the anticipation that it increase inspector accuracy), and even have a sample of signs being measured with a retroreflectometer, thus obtaining documented values to be compared against the standard.

A SIMS can be used as a record-keeping tool that stores record of sign maintenance and inspection shows such tool guides the inspection process and further that a serious effort is being made to inspect and replace signs in a timely manner. This could serve as a degree of protection for the state against liability by showing an aggressive attempt to achieve compliance with the standards. Other benefits of an SIMS include the capability to use laptop computers on nighttime rides to help sign inspectors identify missing signs and running queries to evaluate all signs in a location where there may be a high number of accidents to determine if additional signs or a higher sheeting grade may help reduce accidents. Also, if the system were to include such details as sheeting material lot numbers, signs in different areas can be traced back to matching lot numbers to identify deficient lots and then traced forward again to identify the signs manufactured using that sheeting.

The research team also recommended that the progress and accuracy of the implementation be monitored. This would be beneficial to the state to determine if the approach is evaluating signs as expected. A sample of signs could be measured with a retroreflectometer upon implementation of the approach and again at random year intervals to determine whether an increasing number of signs are meeting the standard or not. The state would need to determine a minimum acceptable percent accuracy and ensure that this percent accuracy is being met. If an adequate amount of improvement in the condition of the signs is not seen, the additional training should be discontinued because the same or similar accuracy rates can be achieved without it. If there is improvement, the desired goal is being met.

Finally, it is important to point out that if another state selected a different set of approaches to evaluate it, it would have to determine a different set of costs and benefits for those approaches. The contribution of this paper, therefore, is in laying out a methodology and framework for doing so. 


\section{REFERENCES}

1. Black, K., McGee, H., and Hussain, S., Implementation Strategies for Sign Retroreflectivity Standard, NCHRP Report 346, Transportation Research Board, Washington, D.C. (April 1992).

2. AASHTO Retroreflectivity Policy Resolution, Minimum Levels of Retroreflectivity for Signs (December 9, 2000)

3. McGee, Hugh and Taori, Sunil, "Impacts on State and Local Agencies for Maintaining Traffic Signs Within Minimum Retroreflectivity Guidelines," BMI, Vienna, VA (1998)

4. McGee, Hugh and Paniati, Jeffrey, An Implementation Guide for Minimum Retroreflectivity Requirements for Traffic Signs, USDOT, FHWA Research and Development, McLean, VA (1998).

5. Kirtley, Nathan and Rasdorf, William, "Sign Count Approximation Using Field Inventory Sampling and Calculated Sign Densities for NC Primary Routes," Technical Report, Department of Civil Engineering, North Carolina State University, Raleigh, NC (December 2001).

6. Palmquist, Marc and Rasdorf, William, "Sign Count Approximation Using Field Inventory Sampling and Calculated Sign Densities: Analysis Improvements, and Methods," Technical Report, Department of Civil Engineering, North Carolina State University, Raleigh, NC (May 2002).

7 Lagergren, Edwin, Traffic Sign Retroreflectivity Measurements Using Human Observers, Olympia, WA: Washington State Department of Transportation, WA-RD 140.1 (December 1987).

8. Huckaby, E., Brown, L., Sears, C., Kittle, L., and Ward, L., "Ensuring Effective Traffic Control Devices with the Millennium Edition of the Manual on Uniform Traffic Control Devices," ITE Journal Volume 71, Number7, Pages 27-32 (July 2001).

9. Hawkins, Jr., Gene, Carlson, Paul, McCaleb, Bradley, and McIlroy, Charles, Impact of Minimum Retroreflectivity Values on Sign Replacement Practices. College Station, Texas: Texas Transportation Institute, Texas A\&M University, TD100: TX 971275-1 (October 1996).

10. Institute of Transportation Engineers, Traffic Signing Handbook, Institute of Transportation Engineers, Washington, D.C., Chapter 2, Pages 23-44 (1997).

11. North Carolina Department of Transportation, Highway and Roadway Mileage. Division of Highways, Geographic Information Systems Unit (January 2000). 
12. "Crashes By Relation to Junction, Traffic Control Devices, and Crash Severity" Traffic Safety Facts, Congressional Information Service, Inc. (1999).

13. Lewis, Russell, "Managing Highway Tort Liability," Transportation Research Board, National Academy Press, Washington D.C. (1994).

14. Retroreflectivity of Roadway Signs for Adequate Visibility: A Guide, Bellamo McGee, Inc. Federal Highway Administration, Washington, D.C. (1999).

15. Vereen, S., Hummer, J. E., and Rasdorf, W., "A Sign Inventory Study to Assess and Control Liability and Cost," Technical Report FHWA/NC/2002-17, North Carolina State University, Raleigh, NC (June 2002). 